$2,5(70,6 \%)$ ở nhóm II. Phục hồi liệt hoàn toàn (Frankel $\mathrm{E}$ ) cả 2 nhóm ở thời điểm khám cuối cùng và không khác biệt về phục hồi chức năng tủy cổ giữa 2 nhóm, tỉ lệ chỉnh gù sau mổ ở nhóm I trung bình là $36^{\circ}$ còn $-6^{0}(96 \%)$ trong khi nhóm II chỉnh gù được $84 \%\left(30^{\circ}\right.$ về $\left.-1^{0}\right)$ [1]. Kết quả nghiên cứu của Zeng và cs báo cáo chỉnh gù cột sống cổ $C 2-C 7$ từ $41,4^{0} \pm 5,2^{\circ}$ trước mổ còn $-4,9^{0} \pm 4,9^{\circ}$ sau mổ.

\section{KẾT LUÂN}

Phẫu thuật điều trị lao cột sống cổ kết quả tốt, vừa chỉnh gù cột sống, vừa không bị đào thải dụng cụ ngay cả khi lao cột sống đang hoạt động và bệnh nhân vận động sớm.

\section{TÀI LIÊU THAM KHẢO}

1. W. Koptan, Y. Elmiligui, M. Elsharkawi (2011). Single stage anterior reconstruction using titanium mesh cages in neglected kyphotic tuberculous spondylodiscitis of the cervical spine. Eur Spine J, 20(2), 308-313.

2. Hao Zeng, Yupeng Zhang, Zheng Liu, et al. (2016). The role of anterior and posterior approaches with circumferential reconstruction without any anterior instrumentation in extended multilevel cervical spinal tuberculosis. int J Clin Exp Med, 9(3), 6190-6199.

3. M. He, H. $\mathrm{Xu}, \mathrm{J}$. Zhao, Z. Wang (2014). Anterior debridement, decompression, bone grafting, and instrumentation for lower cervical spine tuberculosis. Spine J, 14(4), 619-627.

4. M. S. Moon, S. S. Kim, Y. W. Moon, et al. (2014). Surgery-related complications and sequelae in management of tuberculosis of spine. Asian Spine J, 8(4), 435-445.

5. R. Tarantino, L. Nigro, P. Donnarumma, et al. (2017). Cervical reconstruction techniques. After adequate selection of the patient report of a series of 34 patients treated with winged expandable cages. Neurosurg Rev, 40(2), 281-286.

6. L. Nigro, R. Tarantino, P. Donnarumma, et al. (2017). A case of cervical tuberculosis with severe kyphosis treated with a winged expandable cage after double corpectomy. J Spine Surg, 3(2), 304-308.

7. J. Zhang, W. S. He, C. Wang, et al. (2018). Application of vascularized fibular graft for reconstruction and stabilization of multilevel cervical tuberculosis: A case report. Medicine (Baltimore), 97(3), e9382.

\title{
ĐĂC ĐIỂM LÂM SÀNG VÀ HÌNH ẢNH CẮT LỚP VI TÍNH 64 DÃY MẠCH NÃO Ở BỆNH NHÂN CHẢY MÁU NÃO DO Vỡ DỊ DẠNG THÔNG ĐộNG-TĨNH MẠCH NÃO
}

\section{TÓM TẮT.}

Mục tiêu: Mô tả đặc điểm lâm sàng, hình ảnh chụp MSCT 64 dãy ở bệnh nhân chảy máu não do võ̃ dị danng thông đông tînh mạch não (AVM). Đối tượng nghiên cứu: Tất cả các bệnh nhân được chẩn đớán là dị dạng thông động-tĩnh mạch não có biến chứng chảy máu được chụp MSCT 64 dãy não-mạch não điêu trị tại Bệnh viện Bạch Mai từ 10/2019 đển 07/2021. Phương pháp nghiên cứu: Mô tả cắt ngang. Kết quả: Tuổi trung bình của nhóm bệnh nhân AVM vỡ là $43 \pm 14,7$ tuổi, tỳ lệ nam/nữ = 1,27/1. Tiền sử bệnh nhân có nhức đâu trước đó chiếm $69,44 \%$, tiền sử động kinh $25 \%$. Tiền sử gia đình có người bị nhức đâu chiếm tỳ lệ cao nhất chiếm $63,89 \%$, dị dạng mạch ngoài da chiếm $11,11 \%$. Bệnh nhân vào vieên vì buiôn nôn, nôn chiếm tỷ lệ $97,2 \%$, vì đau đâuu chiểm $94,4 \%$, vì liệt nửa người chiếm $50 \%$, vì rối loạn ý thức chiếm $30,56 \%$. Vị trí chảy máu hay gặp là chảy máu thùy.

\footnotetext{
${ }^{1}$ Bệnh viện Bạch Mai

2 Trường Đại họ Y Hà Nôi

${ }^{3}$ Bênh Viện Đa khoa tỉnh Thanh Hóa.

Chịu trách nhiệm chính: Võ Hồng Khôi

Email: drvohongkhoi@yahoo.com.vn

Ngày nhận bài: 8.9.2021

Ngày phản biện khoa học: 27.10.2021

Ngày duyệt bài: 10.11.2021
}

Võ Hồng Khôi i, ${ }^{1,2}$ Lê Hồng Ninh ${ }^{3}$, Nguyễn Hải Anh ${ }^{1}$.

Kích thước khối máu tụ nhỏ, trung bình và lớn lần lượt chiếm $26,47 \%, 41,18 \%$ và $32,35 \%$. Các ổ dị dạng có kích thước nhỏ và trung bình là hay võ̃ nhất chiếm 97,2\%. Nguồn cấp máu cho ổ dị dạng vỡ çủa động mạch não giữa là nhiều nhất chiếm $52,78 \%$. Ổ dị dạng được nuôi bằng 1 đến 3 cuống nuôi (chiếm 91,67\%) và có một tĩnh mạch dẫn lưu duy nhất (chiếm 72,2\%) là những ổ dễ vỡ. Kết luận: Độ tuổi hay gặp nhất của các bệnh nhân AVM võ là trền 40 tuổi chiếm tỷ lệ $63,9 \%$; tuổi trung bình $43 \pm 14,7$. Bệnh gặp ở cả hai giới với tỷ lệ nam/nữ là 1,27/1. Bệnh nhân vào viện vì buồn nôn, nôn chiếm $97,2 \%$, đau đâu $94,4 \%$, liệt nửa người chiếm $50 \%$, rối loạn ý thức $30 \%$, động kinh $13,89 \%$. Chảy máu do võ AVM là chảy máu thùy chiếm $85,72 \%$. Ổ dị dạng vỡ thường là ổ có kích thước nhỏ $<3 \mathrm{~cm}$, có một tĩnh mạch dẫn lưu duy nhất.

Tư khóa: Dị dạng thông động tînh mạch não võ, MSCT 64 dãy não-mạch não.

\section{SUMMARY}

CLINICAL FEATURES AND MSCT IMAGING

IN PATIENTS WITH RUPTURED CEREBRAL ARTERIOVENOUS MALFORMATION

Objectives: To describe clinical features and MSCT imaging in cerebral hemorrhage patients due to ruptured cerebral arteriovenous malformation. Methods: A descriptive cross-sectional study of 36 cases with ruptured cerebral arteriovenous 
malformation (AVM) who were treated at Bach Mai Hospital from October 2019 to July 2021. Results: Mean age was $43 \pm 14,7$ years old, male/female ratio was $1,27 / 1$. Medical history with headache and epilepsy were $69,44 \%$ and $25 \%$, respectively. Family health history record with headache was $63,89 \%$ and cutaneous vessel disorders was $11,11 \%$. Admisssion reasons: nausea/vomitting were $97,2 \%$, headache was $94,4 \%$, altered level of consciousness was $30.6 \%$ and hemiplegia was $50 \%$. The common hemorrhagic location were in cerebral lobules. The percentage of hematoma sizes smaller than $3 \mathrm{~cm}$, from 3 to $6 \mathrm{~cm}$ and greater than $6 \mathrm{~cm}$ were $58.3 \%, 38.9 \%$, and $2.8 \%$ respectively. The most common ruptured AVM size were small and medium. The ruptured AVM feeding vessels originate from midle cerebral artery were $52,78 \%$. The AVM had 1 to 3 feeding arteries were $91,67 \%$. The AVM with pure one draining vein was $72,2 \%$. Conclusion: The predominant age group in ruptured AVM was 40 years old and above $(63,9 \%)$; the mean age was $43 \pm 14,7$, male/female ratio was $1,27 / 1$. The common hemorrhagic location were in cerebral lobules $(85,72 \%)$, hematoma sizes smaller than $3 \mathrm{~cm}$ with pure one draining vein was $72,2 \%$.

Key words: Ruptured cerebral arteriovenous malformation (AVM).

\section{I. ĐĂT VẤN ĐỀ}

Dị dạng động tĩnh mạch não (AVM) là bất thường bẩm sinh mạch máu trong não, xuất hiện do quá trình phát triển bất thường của hệ thống mạch máu, tạo ra sự thông thương trực tiếp giữa các động mạch não với tĩnh mạch não[1]. Dị dạng thông động-tĩnh mạch não gồm có ba thành phần là các động mạch nuôi, ổ dị dạng và tĩnh mạch dẫn lưu [2].

Khoảng 45\% trường hợp AVM bị võ [3], trong đó tỷ lệ tử vong chiếm $10 \%$. Bệnh lý này thường xảy ra ở người trẻ từ 20 đến 40 tuổi [2]. Có đên 88\% bệnh nhân dị dang thông động-tînh mạch não thường không biểu hiện các triệu chứng lâm sàng rõ trong giai đoạn đầu của cuộc đời [3]. AVM chiếm $25 \%$ đột quy xuất huyểt ở người trưởng thành dưới 50 tuổi và có tới $40 \%$ bênh nhân AVM vỡ tử vong hoặc tàn phế trong vòng một năm sau xuất huyết não.

Chụp MSCT 64 dãy não-mạch máu não là kỹ thuật chẩn đoán hình ảnh có nhiều giá trị trong việc đánh giá nhu mô não cũng như khảo sát mạch máu trong não. Một trong những tác dụng quan trong nhất là chẩn đoán dị dạng thông động-tĩnh mạch não. Vì vậy, chúng tôi tiến hành nghiên cứu đề tài với mục tiêu:

Mô tả đặc điểm lâm sàng và hinh ảnh cắt lớp vi tính 64 dãy mạch não ở bệnh nhân chảy máu não do vỡ dị dạng thông động tĩnh mạch não.

\section{II. ĐỐI TƯỢNG VÀ PHƯƠNG PHÁP NGHIÊN CỨU}

2.1 Đối tượng: các bệnh nhân được chẩn đoán là dị dạng thông động-tĩnh mạch não có biến chứng chảy máu được chụp MSCT 64 dãy não-mạch não điều trị tại Bệnh viện Bạch Mai từ 10/2019 đến 07/2021.

2.2 Phương pháp nghiên cứu: Phương pháp mô tả cắt ngang trên $36 \mathrm{ca}$ bệnh. Bệnh nhân nhập viện được khám lâm sàng, làm các xét nghiệm cận lâm sàng, chụp MSCT 64 dãy não-mạch não. Ghi nhận thông tin nghiên cứu theo mẫu bệnh án có sự đồng thuận của bệnh nhân và/hoặc gia đình.

2.3. Xử lý số liệu: Theo phương pháp thông kê y học, sử dụng phần mềm SPSS 25.0

\section{KẾT QUẢ NGHIÊN CỨU}

\subsection{Các đặc điểm cơ bản của bệnh nhân}

Bảng 3.1. Các đăc điểm cơ bản của bệnh nhân

\begin{tabular}{|c|c|c|}
\hline Đặc điểm & $\begin{array}{c}\text { Số bệnh } \\
\text { nhần }\end{array}$ & $\begin{array}{c}\text { Tỷ lệ } \\
\text { (\%) }\end{array}$ \\
\hline Nam & 20 & 55,6 \\
\hline Nữ & 16 & 44,4 \\
\hline \multicolumn{2}{|c|}{ Lý do vào viện } \\
\hline \multicolumn{2}{|c|}{$43 \pm 14,7$ tuối } \\
\hline Rối loạn ý thức & 11 & 30,6 \\
\hline Chóng mặt & 3 & 8,3 \\
\hline Nhức đâu & 34 & 94,4 \\
\hline Buônn nôn, nôn & 35 & 97,2 \\
\hline Cơn động kinh & 5 & 13,9 \\
\hline Tê và/hoặc liệt nưa người & 18 & 50 \\
\hline
\end{tabular}

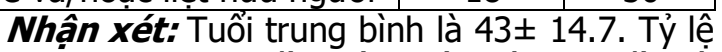
nam/nữ $=1,27 / 1$. Buồn nôn, nôn và đau đầu là̉ những triệu thường gặp khi bệnh nhân nhập viện với tỷ lệ lẩn lượt là $97,2 \%$ và $94,4 \%$.

\subsection{Tiên sử bệnh}

Bảng 3.2. Tiền sử bản thân và gia đình

\begin{tabular}{|c|c|c|}
\hline Đặc điểm & $\begin{array}{l}\text { Số bệ̂nh } \\
\text { nhẩn }\end{array}$ & $\begin{array}{l}\text { Tỷ lệ } \\
(\%)\end{array}$ \\
\hline \multicolumn{3}{|c|}{ Tiền sử bản thân } \\
\hline Động kinh & 9 & 25.00 \\
\hline Nhức đâu & 25 & 69.44 \\
\hline Chấn thương & 0 & 0 \\
\hline Không có tiền sử bệnh & 4 & 11.11 \\
\hline \multicolumn{3}{|c|}{ Tiền sử gia đình } \\
\hline Động kinh & 1 & $2,78 \%$ \\
\hline Nhức đầu & 23 & $63,89 \%$ \\
\hline Dị dạng mạch ngoài da & 4 & $11,11 \%$ \\
\hline $\begin{array}{l}\text { Không có tiền sử bệnh } \\
\text { gia đình }\end{array}$ & 8 & $22,22 \%$ \\
\hline
\end{tabular}

Nhân xét: Số bênh nhân có tiền sử nhức đầu chiếm tỷ lệ nhiều nhất $69,44 \%$. Tiền sử gia đình có người bị nhức đâu cũng chiếm tỷ lệ cao nhất chiếm $63,89 \%$

3.3. Vị trí bAVM võ

Bảng 3.3. Vị trí bAVM võ 


\begin{tabular}{|c|c|c|}
\hline \multicolumn{2}{|c|}{ Vị trí bAVM vỡ } & Tỷ lệ (\%) \\
\hline Thùy trán & 10 & 23,81 \\
\hline Thùy thái dương & 10 & 23,81 \\
\hline Thùy đỉnh & 7 & 16,67 \\
\hline Thùy chấm & 9 & 21,43 \\
\hline Đồi thị, nhân xám, thế chai & 2 & 4,76 \\
\hline Tiếu não & 4 & 9,52 \\
\hline
\end{tabular}

Nhận xét: Vị trí chảy máu hay gặp nhất là chảy máu thùy chiếm $85,72 \%$, chảy máu vùng sâu trong não chiếm tỷ lệ thấp.

3.4. Kích thước ố bAVM võ

Bảng 3.4. Kích thước ổ bAVM võ

\begin{tabular}{|c|c|c|}
\hline $\begin{array}{c}\text { Kích thước ố } \\
\text { AVM }\end{array}$ & $\begin{array}{c}\text { Số bệnh } \\
\text { nhẩn }\end{array}$ & Tỷ lệ \% \\
\hline$<3 \mathrm{~cm}$ & 21 & 58,33 \\
\hline $3-6 \mathrm{~cm}$ & 14 & 38,89 \\
\hline$>6 \mathrm{~cm}$ & 1 & 2,78 \\
\hline Kích thước khối máu tụ \\
\hline$<3 \mathrm{~cm}$ & 9 & 26,47 \\
\hline $3-5 \mathrm{~cm}$ & 14 & 41,18 \\
\hline$>5 \mathrm{~cm}$ & 11 & 32,35 \\
\hline
\end{tabular}

Nhận xét: Số lượng các ổ bAVM vỡ có kích thước < $3 \mathrm{~cm}$ chiếm tỷ lệ lớn nhất với 58,33\%. Kích thước khối máu tụ từ 3-5cm chiếm tỷ lệ lớn nhất với $41,18 \%$.

3.5. Đặc điểm mạch máu của ổ dị dang. Bảng 3.5. Đặc điểm mạch máu của ổ dị dạng

\begin{tabular}{|c|c|c|}
\hline Nguôn cấp máu & $\begin{array}{l}\text { Số bệnh } \\
\text { nhẩn }\end{array}$ & $\begin{array}{l}\text { Tý lệ } \\
\%\end{array}$ \\
\hline ĐM não giữa & 19 & 52,78 \\
\hline ĐM não trước & 9 & 25 \\
\hline ĐM não sau & 12 & 33,33 \\
\hline ĐM tiếu não sau dưới & 1 & 2,78 \\
\hline ĐM tiếu não trước dưới & 1 & 2,78 \\
\hline ĐM tiếu não trên & 2 & 5,56 \\
\hline \multicolumn{3}{|c|}{ Số lượng cuống nuôi } \\
\hline 1 động mạch nuôi duy nhất & 13 & 36.11 \\
\hline 2 động mạch nuối & 14 & 38.8 \\
\hline 3 động mạch nuôi & 6 & 16.66 \\
\hline$\geq 4$ động mạch nuôi & 3 & 8.33 \\
\hline \multicolumn{3}{|c|}{ Số lượng tĩnh mạch dân lưu } \\
\hline 1 tĩnh mạch dân lưu & 26 & 72.2 \\
\hline$\geq 2$ tĩnh mạch dân lưu & 10 & 27.8 \\
\hline
\end{tabular}

Nhận xét: Nguồn cấp máu cho AVM từ động mạch não giữa là nhiều nhất chiếm 52,78\%. AVMM được nuôi bằng 1 cuống nuôi chiếm tỷ lệ nhiều nhất với $36,11 \%$. Trong khi đó, AVM có 1 tĩnh mạch dẫn lưu cũng chiếm đa số với $72,2 \%$.

\section{BÀN LUÂN}

Tuổi trung bình của nhóm nghiên cứu là $43 \pm$ 14,7 dao động từ 28,3 đến 57,7 tuổi. Nhóm tuổi thường gặp nhất là trên 40, chiếm tỷ lệ $63,9 \%$. Theo Phan Văn Đức [4] tuối trung bình khi phát hiện bệnh nhân AVM là $34,87 \pm 14,38$. Theo
Marco [5] tuổi trung bình là 31. Như vậy, độ tuổi phát hiện $A V M$ võ trong nghiên cứu của chúng tôi là cao hơn so với các nghiên cứu trong nước và quốc tế điều này có thể lý giải do kích thước cõ mẫu chưa đủ lớn.

Các dị dạng thông động-tĩnh mạch não thường không biểu hiện triệu chứng lẩm sàng trong giai đoạn đầu của cuộc đời. Tiên sử bệnh nhân có thể có biểu hiện nhức nửa đầu kiểu Migraine cũng có thể nhức đầu liên tục kéo dài và không có tính chất gì đặc biệt; có thể có những cơn co giật động kinh cục bộ hoặc động kinh toàn thể hoá thứ phát. Trong nghiên cứu của chúng tôi, bệnh nhân có tiên sử nhức đâu khá cao chiếm $69,4 \%$, tiền sử động kinh chiếm $25 \%$, tương tự nghiên cứu của các tác giả khác [4], [5]. Về tiền sử bệnh gia đình, trong nghiên cứu có 23 bệnh nhân (chiếm 63,9\%) người trong gia đình có bố me hoăc anh chi em có tiền sử nhức đầu. Tuy nhiên, không ghi nhận mối liên hệ với các bệnh lý dị dạng mạch máu não.

Triệu chứng khi vào viện chiếm tỷ lê cao nhất là nôn hoăc/và buồn nôn $(97.2 \%)$, nhức đầu với tính chất dữ dội chiếm $94,4 \%$ các triệu chứng trên là hậu quả của chảy máu gây ra tăng áp lực trong sọ hoặc kích thích trực tiếp vào trung tâm nôn ở sàn não thất IV. Trong nghiên cứu của chúng tôi, có 11 trường hợp bệnh nhân rối loạn ý thức (chiếm 30,6\%). Trong đó, duy nhất một trường hợp có điểm Glasgow là 8 , số còn lại dao động từ từ 10 đến 14 điểm. Như vậy bệnh nhân $A V M$ não võ vào viện vì rối loạn ý thức thường không biểu hiện rầm rộ, điều này có thể lý giải do bểnh hơc của chảy máu não căn nguyên AVM là do võ̃ tînh mạch (Deruty [6]). Tê và liệt nửa người cũng là các triệu chứng thường gặp với tỷ lệ $50 \%$ và $52,9 \%$.

Vị trí chảy máu hay gặp nhất là chảy máu thùy chiếm $85,72 \%$, chảy máu vùng sâu trong não chiếm tỷ lệ thấp. Kết quả này tương tự với nghiên cứu của Phan Văn Đức [4], Phạm Hồng Đức [7] và Marco [5].

Kích thước khối máu tụ nhỏ trong nghiên cứu của chúng tôi chiếm tỷ lệ $26,47 \%$, khối máu tụ trung bình chiếm tỷ lệ $41,18 \%$, kích thước khổi máu tụ lớn chiếm tỷ lệ 32,35\%. Theo kết quả nghiên cứu của Phan Văn Đức [4] trên 41 bệnh nhân AVM võ có khối máu tụ trong não thì tỷ lệ có khối máu tu có kích thước trung bình và lớn là $73,53 \%$. Kích thước khối máu tụ là yếu tố tiên lượng đến kết cục lâm sàng cũng như triệu chứng nhập viện của bệnh nhân.

Trong nghiền cứu của chúng tôi, số AVM võ có kích thước nhỏ và trung bình chiếm 97,22\%, 
tương tự nghiên cứu của Pham Hồng Đức [7] và Marco [5]. Như vậy kích thước ổ dị dạng vỡ theo nhiều nghiên cứu có liên quan đến hiện tượng chảy máu não. Ổ dị dạng có kích thước nhỏ và trung bình có nguy cơ võ cao hơn ổ có kích thước lớn.

Động mạch não giữa tham gia cấp máu cho ổ dị dạng chiếm $52,78 \%$ các trường hợp, động mạch não trước là $25 \%$, động mạch não sau là 33,33\%. Ngoài ra một số ổ dị dạng còn được cấp máu bởi các nhánh động mạch tiểu não. Kết quả này phù hợp với nhận định của Pham Hồng Đức [7] cho rằng khu vực động mạch nã̇o giữa là khu vực hay gặp nhất vì động mạch não giữa là một động mạch lớn và là nguồn cung cấp máu cho phần lớn bán cầu não của hệ tuần hoàn trước.

Trong nghiên cứu của chúng tôi phần lớn các ổ dị dạng võ có từ hai cuống mạch nuôi trở lên $(63,89 \%)$, các ổ dị dang vỡ thường là những ổ có một tĩnh mạch dẩn lưu duy nhất $(72,2 \%)$, điều này cũng tương tự với các nghiên cứu của nhiều tác giả khác.

\section{KẾT LUÂNN}

Độ tuổi hay gặp nhất của các bệnh nhân AVM võ là từ trên 40 tuổi chiếm tỷ lệ 63,9\%; tuổi trung bình $43 \pm 14,7$. Bệnh gặp ở cả hai giới với tỷ lệ nam/nữ là 1,27/1. Chảy máu do vỡ AVM là chảy máu thùy chiếm $85,72 \%$. Ổ dị dạng võ thường là ổ có kích thước nhỏ $<3 \mathrm{~cm}$, có một tĩnh mạch dẫn lưu duy nhất.

\section{TÀI LIÊU THAM KHẢO}

1. Friedlander RM. Arteriovenous malfor- mations of the brain. N Engl J Med 2007; 356:2704-12.

2. Cognard C, Spelle L., and Pierot L. (2004), Pial arteriovenous malformations in: Intracranial vascular malformations and aneurysm, Springer. 39-92.

3. Shaligram S.S., Winkler E., Cooke D. và công sứ. (2019). Risk factors for hemorrhage of brain arteriovenous malformation. CNS Neurosci Ther, 25(10), 1085-1095.

4. Phan Văn Đức, Lê Văn Thính, Hoàng Văn Thuân (2018), siêu âm Doppler xuyên so và hình ảnh chụp mạch máu não của dị dạng thông đông-tĩnh mach nã̃o.

5. Marco A.Stefani, Phillip J.Porter, et al (2002), Large and deep brain arteriovenous malformation are associated with risk of future hemorrhage, Stroke, 3. 1220.

6. Deruty $R$, et al (1985), Les malformations Arterio-veineuses Cerebrales, Neurochir, 31. 21-29

7. Pham Hồng Đức, Pham Minh Thông, Lê Văn Thính (2010), Các yễu tố cấu trúc mạch liên quan đên biểu hiện xuất huyết của dị dạng động tînh mach não, Tạp chí $Y$ học thực hành $(705)$ số 2, 52-55.

\section{TÌM HIỂU MộT Số YẾU TỐ LIÊN QUAN ĐẾN KẾT QUẢ KIỂM SOÁT HUYẾT ÁP Ở BÊ̂NH NHÂN TĂNG HUYẾT ÁP ĐIỀU TRI NGOẠI TRÚ TẠI BÊ̂NH VIÊ̂N ĐA KHOA HUYỆN LỤC NGẠN}

\section{TÓM TẮT}

Mục tiêu: Tìm hiểu một số yếu tố liên quan đến kết quả kiểm soát huyết áp ở bệnh nhân tăng huyết áp điêu trị ngoại trú tại Bệnh viện Đa khoa huyện Lục Ngạn năm 2020. Đối tượng và phương pháp nghiên cứu: Nghiên cứu mồ tả cắt ngang được thực hiện từ tháng 7/2020 đến tháng 10/2021 trền 500 bệnh nhân tăng huyết áp được điều trị ngoại trú tại Bệnh viện Đa khoa huyện Lục Ngạn. Kết quả: Tỉ lệ đạt huyết áp mục tiêu là $25,6 \%$, nữ cao hơn nam với tỉ lê $31,6 \%$ và $18,6 \%$, tuân thủ thuốc đat $76 \%$. Có mối liên quan giữa giới tính $(p=0,001)$, tiền sử gia đình bị tăng huyết áp $(p=0,022)$, bệnh đái tháo đường

\footnotetext{
${ }^{1}$ Trường Đại học Y Hà Nội,

${ }^{2}$ Viện Tim mach Viêt Nam-Bênh viên Bach Mai

Chịu trách nhiệm chính: Đồng Thị Ngọc Lâm

Email: khileocay47@gmail.com

Ngày nhận bài: 9.9.2021

Ngày phản biên khoa hoc: 25.10.2021

Ngày duyệt bài: 10.11.2021
}

Đồng Thị Ngọc Lâm 1 , Nguyễn Thị Bạch Yến ${ }^{2}$

kèm theo $(p=0,025)$, thời gian bị tăng huyết áp $(p=0,033$ và 0,028$)$, số nhóm thuốc huyết áp và tổng số thuốc sử dụng hàng ngày với kết quả kiểm soát huyết áp $(p<0,001)$. Kết luận: Có mối liên quan giữa giới tính, tiền sử gia đình bị tăng huyết áp, bệnh đái tháo đướng kèm theo, thời gian bị tăng huyết áp, số nhóm thuốc huyết áp và số thuốc sử dụng hàng ngày với kết quả kiểm soát huyết áp.

Tư khóa: các yếu tố liên quan đến kiểm soát huyết áp.

\section{SUMMARY}

\section{TO STUDY SOME FACTORS RELATED TO THE RESULTS OF BLOOD PRESSURE CONTROL IN HYPERTENSIVE PATIENTS TREATED AS OUTPATIENTS AT LUC NGAN DISTRICT GENERAL HOSPITAL}

Objectives: To study some factors related to the results of blood pressure control in hypertensive patients treated as outpatients at Luc Ngan District General Hospital in 2020. Subjects and methods: A 